\title{
28 Research Suare \\ Hypertension associated with unhealthy lifestyle and marked by serum cortisol levels
}

Chunsong Hu ( $\nabla$ cnhucs@163.com )

Nanchang University https://orcid.org/0000-0002-0590-3909

\section{Yanqing Wu}

the Second Affiliated Hospital of Nanchang University

Juxiang Li

the Second Affiliated Hospital of Nanchang University

\section{Menghong Wang}

the First Affiliated Hospital of Nanchang University

\section{Yuzhi Ge}

Affiliated People's Hospital of Nanchang University

\section{Tengiz Tkebuchava}

Boston TransTec, LLC, Boston

Qinghua Wu

the Second Affiliated Hospital of Nanchang University

\section{Biological Sciences - Article}

Keywords: cardiovascular disease, cortisol, hypertension, lifestyle, risk factors

Posted Date: August 26th, 2021

DOI: https://doi.org/10.21203/rs.3.rs-824235/v1

License: (1) (1) This work is licensed under a Creative Commons Attribution 4.0 International License. Read Full License 


\section{Abstract}

There are more and more individuals with hypertension due to major risk factors (mRFs) related to unhealthy lifestyle. Here, we report that a new type of hypertension associates with unhealthy lifestyle and marks by serum cortisol levels, which is termed C-type hypertension (CtH). All subjects collected at random at outpatient department between 2012 and 2017, with or without family history of hypertension, with or without unhealthy "environment-sleep-emotion-exercise-diet" intervention [E(e)SEEDi] related mRFs, were screened and measured serum cortisol levels (8:00 AM and 4:00 PM) and blood pressure. Typical cases with $\mathrm{CtH}$ have unhealthy E(e)SEEDi related mRFs, such as stay up later or OSA (+++), psychological pressure or bad emotion, lack of physical exercise or sitting for a long time, heavy smoking and/or liquor drinking. Day serum cortisol levels (8:00 AM and 4:00 PM) in this group were significantly elevated (vs control group, $\mathrm{P}<0.01$ ). Follow-up analysis showed that the outcomes were closely linked to these individuals' lifestyle and adherence to treatment. In conclusion, this study suggested that there is indeed $\mathrm{CtH}$. Most are young and middle-aged individuals and easy to suffer from major adverse cardiovascular events (MACEs).

\section{Introduction}

Hypertension has become one of the common major non-communicable diseases (mNCDs) that endanger human health, and it brings heavy burden to global public health. Currently, the total number of hypertensive patients in China has exceeded 330 million. One in every three adults suffers from hypertension, while another 130 million patients do not know that they have hypertension. Even among the patients receiving treatment, up to $75 \%$ of them have uncontrolled blood pressure. That is to say, the "three rates" (awareness rate, treatment rate and control rate) of hypertension in China are still low. Almost $50 \%$ of Chinese adults over 35 years have hypertension ${ }^{1}$. According to the revised diagnostic criteria for hypertension $(>130 / 80 \mathrm{mmHg})$ in the US in $2017^{2}$, the prevalence of hypertension in China has exceeded $60 \%$ and the number of patients is estimated to exceed 600 millions $^{3}$. Therefore, paying attention to early screening, early diagnosis, early treatment and prevention of hypertension is of great significance for reducing target organs damage and high mortality and disability rate, and for global economic and social development.

Although we already knew in 1970s that there is a linkage between stress and cardiovascular disease ${ }^{4}$, there were a few reviews on cortisol-induced hypertension as a hypothesis ${ }^{5}$, and the effects of cortisol on targeted organs such as brain, heart, kidneys, and blood vessels as well as its related mechanisms remain unclear ${ }^{6,7}$. In this study, we reported a novel type of secondary hypertension associated with unhealthy lifestyle as new stress factors and marked by serum cortisol levels, and termed it as "C-type hypertension (CtH)".

\section{Results}

Brief introduction of clinical presentation of four typical cases of $\mathrm{CtH}$ as follows: Table 1 (Case 1, Case 2, Case 3, and Case 4).

The results of blood pressure elevation and cortisol level of peripheral blood in 15 patients with typical $\mathrm{CtH}$ (6 males and 6 females) were as follows (Table 2, Table 3). There was a significant difference between patients in 
Table 1 or Table 2 and 3 healthy controls (Table 4, 2 males and 1 females) $(P<0.01)$.

Cortisol levels in $\mathrm{CtH}$ patients during the day (8:00 Am and 4:00 Pm) was significantly higher than that in healthy controls $(P<0.01)$, but there was no significant difference between male and female patients $(P>0.05)$. It accorded with the main clinical characteristics of temporarily sharply or sustained slowly increase of cortisol levels, and improved lifestyle and antihypertensive therapy can keep cortisol levels in normal range. The outcome of follow-up analysis was also related to the improvement of patients' lifestyle and adherence to treatment (Fig 1). In addition, preliminary clinical data of elderly patients with hypertension or diabetes mellitus showed that cortisol levels were basically within the normal range (Table 5), which may also be related to the number of samples.

\section{Discussion}

As we known, mNCDs including hypertension share one or more modifiable lifestyle risk factors ${ }^{8}$, such as abnormal internal environment (hypertension, hyperglycemia, dyslipidemia, obesity, and chronic infection and inflammation), sedentary lifestyle or physical inactivity, alcohol consumption, cigarette smoking, and poor nutrition. Lifestyle modification may lower BP in the population ${ }^{9}$, or prevention and control of hypertension can be achieved through targeted and/or population-based unhealthy lifestyle strategies ${ }^{10}$. The combination of reduced sodium intake and the DASH (Dietary Approaches to Stop Hypertension) diet may lower systolic blood pressure $^{11}$. Both American College of Cardiology (ACC)/American Heart Association (AHA) and European Society of Cardiology (ESC)/European Society of Hypertension (ESH) blood pressure guidelines recommended healthy lifestyle including exercise, body weight reduction, low to moderate alcohol intake, a low-sodium diet, and adequate potassium intake for prevention of elevated blood pressure ${ }^{12}$.

Since long-term working at department of cardiovascular disease (CVD), Dr. Hu has to face to face with hypertensive patients. In the process of careful inquiry and consultation according to the previously creatively established by five core elements of health, that is, "environment-sleep-emotion-exercise-diet" intervention $[E(e) S E E D i]^{13-15}$, and teaching the curriculum "Health Assessment" for medical students, Dr. Hu paid special attention to the association of unhealthy lifestyle related major risk factors with hypertension or coronary heart disease, and expected assessing these cardiovascular risk factors due to applying for "Grand Challenges Explorations" projects (unfortunately, not funded).

Hypertension caused by unhealthy lifestyle (a secondary hypertension) is deeply impressed, especially, after participated in medical students and postgraduates' physical examination for many times. It was found that many young students were long-term staying up late to study, not enough sleep and psychological pressure during their professional examinations, Most of these young adults have elevated blood pressure due to sedentary lifestyle, physical inactivity and coffee drinking. After literature search and in-depth thinking and analysis, it is found that this kind of hypertension related to "new typical stress" caused by unhealthy lifestyle is mainly characterized by temporary sharp increase or sustained slow increase of serum cortisol levels as a 
biomarker, and has been confirmed by reliable data in this paper. Therefore, this new type of hypertension discovered have been named as "C-type Hypertension (CtH)"16-18.

It is well known that hypertension includes essential hypertension (about 95\%) and secondary hypertension (about 5\%). In addition to renal diseases, the latter is mainly caused by unhealthy lifestyle, and also known as "lifestyle disease" or "wealth disease". Due to the prevalence of modem unhealthy lifestyle, such as e-life related e-noise ${ }^{19}, \mathrm{CtH}$ has become more and more common in clinical practice among young and middle-aged individuals. For example, moderate or severe OSA (apnea hypopnea index $\geq 20 / \mathrm{h}$ or even $\geq 30 / \mathrm{h}$ ) during rapid eye movement sleep was significantly associated with prevalent hypertension ${ }^{20}$.

The so-called "new typical stress" caused by unhealthy lifestyle mainly refers to those related to five core factors of health. For example, major depression is associated with an increased risk of hypertension and coronary artery disease as well as acute cardiovascular events ${ }^{21}$, such as myocardial infarction and chronic heart failure. Not only emotional and psychological stress, but also stress from abnormal environment (for example, external environment, water-air-soil-sound pollution; Or internal environment, chronic inflammation, vascular injury and other diseases), stress from sleep disorders (OSA, staying up late, shifting, insomnia, etc.), stress from exercise linked disorders (sedentary lifestyle, lack of physical activity, and obesity; Or intense exercise, physical overload, etc.); And stress from dietary disorders (excessive salt, cigarette smoking, drinking, or inadequate water and fresh fruit intake $)^{22}$. For example, high salt intake increased blood pressure in chimpanzees ${ }^{23}$, cigarette smoking among women was associated with an increased risk of developing hypertension ${ }^{24}$. These "new typical pressures" were found to link with the change of biomarker cortisol levels in serum, which ultimately induced CtH.

However, several studies found that improved diet quality could attenuate genetic risk for obesity and reduce risk of incident hypertension ${ }^{25,26}$, and was consistently associated with a decreased risk of death ${ }^{27}$. In fact, lifestyle modification, such as adequate sleep, aerobic exercise, healthy diet habits can lower the risk of not only CVD but also diabetes, cancer, and related CDC strips or Re-CDC strips ${ }^{28}$.

A recent work confirmed that unhealthy lifestyle linked with high serum cortisol levels ${ }^{29}$. There were also high cortisol levels in pregnancy induced hypertension patients ${ }^{30}$. Hence, whether is high blood pressure during pregnancy a special CtH due to "internal environment changing" among younger women or not, it needs further investigation, but we already known that women with hypertensive disorders of pregnancy in their first pregnancy had increased rates of chronic hypertension and development of risk factors for CVD ${ }^{31}$, and these women may also benefit from lifestyle intervention. 
Previous studies showed that hypertensive and normotensive individuals who adhere multiple lifestyle modifications (e.g., Aerobic exercise or the DASH diet plus physical activity and weight control) could improve control of blood pressure and reduce the risk for CVD ${ }^{32-34}$. In recent years, healthy lifestyle is widely recommended for hypertension and CVD ${ }^{35,36}$. However, lifestyle changes to treat hypertension needs to improve the adherence since younger individuals and those with lower educational attainment and lower income were, in general, less likely to adhere lifestyle behaviors for blood pressure control ${ }^{37,38}$. In addition, since impaired vascular function may contribute to exaggerated blood pressure responses during daily living ${ }^{39}$, hence, aerobic exercise as a part of the ideal lifestyle is very suitable for patients with $\mathrm{CtH}$, and exercise-testing (Bruce protocol) ${ }^{40}$ may be a useful tool to evaluate these patients.

Thus, early lifestyle modifications should be recommended not only for preventing atherosclerotic CVD and diabetes $^{41-43}$, but also for hypertension according to this study. In fact, one year of lifestyle intervention may lower hypertension ${ }^{51}$. Lifestyle modifications by regular exercise and weight reduction had already been recommended for the first time with class I, level of evidence A for the management of hypertension by ESH and ESC guidelines in $2013^{12,45}$. Obviously, the guideline-based management was beneficial for hypertension control ${ }^{46}$.

All in all, CtH was discovered in our clinical practice. It is characterized by a temporary sharp or sustained slow increase of the serum biomarker cortisol level. Cortisol's first letter is C, so it is called "C-type hypertension". CtH is worth establishing and screening animal models and conducting in-depth basic research so as to disclose the pathogenesis and vital pathogenic genes. Whether the levels of urinary cortisol ${ }^{47}$ is also a biological biomarker, it still waits for our study. The pro-inflammatory role and adverse effects of cortisol dysregulation is an alarm clock of MACEs ${ }^{48}$ since increased cortisol levels were predictive of acute mortality ${ }^{49}$.

There are several limitations of this study. First, it was only a preliminary report from a clinical observational study. Second, as a new discovery in clinical practice, it was restricted by scientific research funds for further basic and translational development. Hence, further large-scale clinical trials which based on current study is highly recommended confirming the role of unhealthy and/or healthy $\mathrm{E}(\mathrm{e}) \mathrm{SEEDi}$ lifestyle on $\mathrm{CtH}$. In addition, it needs to further explore which cortisol levels in serum, saliva, hair, and urine is better as a biomarker of $\mathrm{CtH}$.

In conclusion, there is indeed a new type of hypertension termed $\mathrm{CtH}$ which is associated with unhealthy lifestyle and marked by temporarily sharply or continuously slowly rising serum cortisol levels. Most are young and middle-aged individuals and are easy to suffer from MACEs. Since healthy E(e)SEEDi can lower the risk of CVD, diabetes, and cancer, it should be prescribed to all hypertensive individuals, especially $\mathrm{CtH}$. 


\section{Methods}

\section{Data Collection}

Patients were randomly enrolled at outpatients department with hypertension from 2012 to 2017, those with or without family history of hypertension, with or without unhealthy lifestyles, including abnormal home or work environment (air pollution, radiation, all kinds of noise), abnormal internal environment (chronic inflammation, high blood sugar or dyslipidemia); Abnormal sleep quality (OSA, staying up late, shifting, insomnia, etc.); Longterm stress, anxiety or depression; Physical inactivity or obesity; And unscientific and non-rational diet, unbalanced nutrition (excessive salt, heavy smoking and drinks), excessive intake of red meat, inadequate water, fruits and vegetables intake not enough.

\section{Clinical investigations}

Patients were examined by physical examination and biochemical examination (including routine blood and urine, liver and kidney function, fasting blood glucose, blood lipid, blood viscosity, uric acid, myocardial enzymes, troponin I, oral administrative glucose tolerance test or postprandial 2-hour blood sugar), hepatitis virus examination, four items of tumors, carbohydrate antigen, prostatic antigen and other related auxiliary examinations (including chest $\mathrm{X}$-ray, routine electrocardiogram and exercise test and 24-hour ambulatory electrocardiogram, ambulatory blood pressure monitoring, color Doppler ultrasound, computer tomography (CT) or magnetic resonance imaging (MRI), coronary angiography, mammography, etc). Relevant data were retained for analysis.

\section{Serum cortisol assay}

Cortisol levels in serum ${ }^{50,51}$, saliva ${ }^{52,53}$, hair ${ }^{54}$, and urine ${ }^{55,56}$ had been measured successfully. In this study, we assayed serum cortisol levels at 8:00 AM and 16:00 PM with previously documented methods. The samples for serum cortisol $(0.5 \mathrm{ml})$ were transported to the laboratory either immediately or the next morning after being stored in a refrigerator at $4{ }^{\circ} \mathrm{C}$ overnight. Serum cortisol levels were measured using commercial kits by radioimmunoassay (Northern Biotechnology Institute, Beijing, China) or chemiluminescent immunoassay (Di'anhuaxing Medical Laboratory, Jiangxi, China). Interassay and intraassay coefficients of cortisol variations were $4.7 \%$ and $10.4 \%$, respectively. Detection limit for cortisol was $14 \mathrm{nmol} / \mathrm{L}$.

\section{Informed consent}

Data collection was followed by a study protocol that was approved by the local ethics committee with reference numbers 0312/2012. It was conducted in accordance with the Helsinki Declaration of 1975, as revised in 2000, and all enrolled patients gave written informed consent. No potential sources of bias. 


\section{Statistical analysis}

The results of original records were used. Data were statistically analyzed using the Statistical Package for the Social Sciences (SPSS version 17.0, SPSS Inc., Chicago, IL, USA) with t-test for comparisons between two groups. A $P$-value of $<0.05$ was considered statistically significant.

\section{Declarations}

\section{Ethics statement}

This work was approved by Human Research Ethics Committee of the Nanchang University, Hospital of Nanchang University, Jiangxi Academy of Medical Science (approval 20120312).

\section{Role of the funding source}

No funding was received for this study. All authors had full access to all study data, and the corresponding author had final responsibility for the decision to submit for publication.

Reporting Summary. Further information on research design is available in the Nature Research Reporting Summary linked to this article.

\section{Data availability}

The data that support the findings of this study are not publicly available but are available upon reasonable request from the corresponding author.

\section{Acknowledgments}

The reviewers and editors are gratefully acknowledged for critical review. The authors also acknowledge the contribution of the all staffs who participated in this study.

\section{Contributions}

C.H. designed the study, collected and analyzed all data, performed statistical analyses, wrote original draft and revised the final manuscript, and contributed to writing-review \& editing; Y.W., J.L., M.W., Y.G. and T.T. contributed to interpretation of data and data evaluation, writing-review \& editing; Q.W. contributed to supervision, interpretation of data and data evaluation, writing-review \& editing. All authors discussed the results, critically reviewed the paper, and approved the manuscript for submission. 
Corresponding authors

Correspondence to Chunsong Hu or Qinghua Wu.

\section{Ethics declarations}

Competing interests

The authors declare no competing interests.

\section{References}

1. Lu, J. et al. Prevalence, awareness, treatment, and control of hypertension in China: data from million adults in a population-based screening study (China PEACE Million Persons Project). Lancet 390, 2549-2558 (2017).

2. Bakris, G. \& Sorrentino, M. Redefining Hypertension - Assessing the New

Blood-Pressure Guidelines. N Engl J Med 378, 497-499 (2018).

3. Yang, C. et al. Prevalence and treatment of hypertension in China: impacts of 2017 American College of Cardiology/American Heart Association High Blood Pressure Guideline. Sci Bull 63, 488-493 (2018).

4. Selye H. The evolution of the stress concept. Stress and cardiovascular disease. Am J Cardio/ 26, 289299 (1970).

5. Whitworth, J. A., Kelly, J. J., Brown, M. A., Williamson, P. M. \& Lawson, J. A. Glucocorticoids and hypertension in man. Clin Exp Hypertens 19, 871-884 (1997).

6. Whitworth, J. A., Brown, M. A., Kelly, J. J. \& Williamson, P. M. Mechanisms of cortisol-induced hypertension in humans. Steroids 60, 76-80 (1995).

7. Whitworth, J. A., Brown, M. A., Kelly, J. J. \& Williamson, P. M. Experimental studies on cortisol-induced hypertension in humans. J Hum Hypertens 9, 395-399 (1995).

8. Arena, R. et al. Healthy lifestyle interventions to combat noncommunicable disease-a novel nonhierarchical connectivity model for key stakeholders: a policy statement from the American Heart Association, European Society of Cardiology, European Association for Cardiovascular Prevention and Rehabilitation, and American College of Preventive Medicine. Eur Heart J 36, 2097-2109 (2015).

9. Pazoki R, Dehghan A, Evangelou E, et al. Genetic Predisposition to High Blood Pressure and Lifestyle Factors: Associations With Midlife Blood Pressure Levels and Cardiovascular Events. Circulation 137, 653-661 (2018).

10. Carey, R. M., Muntner, P., Bosworth, H. B. \& Whelton, P. K. Prevention and Control of Hypertension: JACC Health Promotion Series. J Am Coll Cardiol 72, 1278-1293 (2018). 
11. Juraschek, S. P., Miller, E. R. $3^{\text {rd }}$., Weaver, C. M. \& Appel, L. J. Effects of Sodium Reduction and the DASH Diet in Relation to Baseline Blood Pressure. J Am Coll Cardiol 70, 2841-2848 (2017).

12. Bakris, G., Ali, W. \& Parati, G. ACC/AHA Versus ESC/ESH on Hypertension Guidelines: JACC Guideline Comparison. J Am Coll Cardiol 73, 3018-3026 (2019).

13. Hu, C. Grants supporting research in China. Eur Heart J 39, 2342-2344 (2018).

14. Hu, C. S. \& Tkebuchava, T. New “P” in Medical Model. Chin Med J (Engl) 129, 492-493 (2016).

15. Hu, C. S. \& Tkebuchava, T. SEEDi $i^{1.0-3.0}$ strategies for major noncommunicable diseases in China. J Integr Med 15, 265-269 (2017).

16. Hu, C. S., Tkebuchava, T., Wu, Q. H. \& Hu, D. Y. C-type hypertension: an ignored new killer? Cardiology Plus 2, 14 (2017).

17. Hu, C. C-type Hypertension. Eur Heart J 40, 715 (2019).

18. Hu, C. S., Wu, Q. H., Hu, D. Y. \& Tkebuchava, T. Novel strategies halt cardiovascular, diabetes, and cancer strips. Chronic Dis Transl Med 3, 159-164 (2017).

19. Hu, C. \& Tkebuchava, T. E-noise: An increasingly relevant health risk. J Integr Med 17, 311-314 (2019).

20. Appleton, S. L. et al. Hypertension Is Associated With Undiagnosed OSA During Rapid Eye Movement Sleep. Chest 150, 495-505 (2016).

21. Nemeroff, C. B. \& Goldschmidt-Clermont, P. J. Heartache and heartbreak-the link between depression and cardiovascular disease. Nat Rev Cardiol 9, 526-539 (2012).

22. Du, H. et al. China Kadoorie Biobank Study. China Kadoorie Biobank Study. China Kadoorie Biobank Study. Fresh Fruit Consumption and Major Cardiovascular Disease in China. N Engl J Med 374, 1332-1343 (2016).

23. Denton, D. et al. The effect of increased salt intake on blood pressure of chimpanzees. Nat Med 1, 10091016 (1995).

24. Bowman, T. S., Gaziano, J. M., Buring, J. E. \& Sesso, H. D. A prospective study of cigarette smoking and risk of incident hypertension in women. J Am Coll Cardiol 50, 2085-2092 (2007).

25. Wang, T. et al. Improving adherence to healthy dietary patterns, genetic risk, and long term weight gain: genediet interaction analysis in two prospective cohort studies. BMJ 360, j5644 (2018).

26. Buendia JR, Li Y, Hu FB, et al. Long-term yogurt consumption and risk of incident hypertensionin adults. J Hypertens 36, 1671-1679 (2018).

27. Sotos-Prieto, M. et al. Association of Changes in Diet Quality with Total and Cause-Specific Mortality. N Engl J Med 377, 143-153 (2017). 
28. Hu, C. S., Wu, Q. H. \& Hu, D. Y. Cardiovascular, diabetes, and cancer strips: evidences, mechanisms, and classifications. J Thorac Dis 6, 1319-1328 (2014).

29. Inoue, K., Hashioka, S., Takeshita, H., Kamura, M. \& Fujita, Y. High Serum Cortisol Levels as a Potential Indicator for Changes in Well-Regulated Daily Life among Junior High School Students. Tohoku J Exp Med 249, 143-146 (2019).

30. Furuhashi, N. et al. Serum cortisol levels in pregnancy induced hypertension patients. Tohoku J Exp Med 149, 21-24 (1986).

31. Stuart, J. J. et al. Hypertensive Disorders of Pregnancy and Maternal Cardiovascular Disease Risk Factor Development: An Observational Cohort Study. Ann Intern Med 169, 224-232 (2018).

32. Whelton SP, Chin A, Xin X, He J. Effect of aerobic exercise on blood pressure: a meta-analysis of randomized, controlled trials. Ann Intern Med 136, 493-503 (2002).

33. Gordon, N. F. et al. Effectiveness of therapeutic lifestyle changes in patients with hypertension, hyperlipidemia, and/or hyperglycemia. Am J Cardio/ 94, 1558-1561 (2004).

34. Elmer, P. J. et al. PREMIER Collaborative Research Group. Effects of comprehensive lifestyle modification on diet, weight, physical fitness, and blood pressure control: 18-month results of a randomized trial. Ann Intern Med 144, 485-495 (2006).

35. LeFevre, M. L. U.S. Preventive Services Task Force. Behavioral counseling to promote a healthful diet and physical activity for cardiovascular disease prevention in adults with cardiovascular risk factors: U.S. Preventive Services Task Force Recommendation Statement. Ann Intern Med 161, 587-593 (2014).

36. Janke, E. A., Richardson, C. \& Schneider, K. L. Society of Behavioral Medicine Executive Committee. Beyond Pharmacotherapy: Lifestyle Counseling Guidance Needed for Hypertension. Ann Intern Med 170, 195-196 (2019).

37. Gee, M. E. et al. Prevalence of, and barriers to, preventive lifestyle behaviors in hypertension (from a national survey of Canadians with hypertension). Am J Cardiol 109, 570-575 (2012).

38. Yao, D. K., Su, W., Zheng, X. \& Wang, L. X. Knowledge and Understanding of

Hypertension Among Tibetan People in Lhasa, Tibet. Heart Lung Circ 25, 600-606 (2016).

39. Thanassoulis, G. et al. Relations of exercise blood pressure response to cardiovascular risk factors and vascular function in the Framingham Heart Study. Circulation 125, 2836-2843 (2012).

40. Luitingh, T. L. et al. A Cross-Sectional Study of the Prevalence of Exercise-Induced Hypertension in Childhood Following Repair of Coarctation of the Aorta. Heart Lung Circ 28, 792-799 (2019).

41. Cheung, B. M. et al. 2016 Consensus statement on prevention of atherosclerotic cardiovascular disease in the Hong Kong population. Hong Kong Med J 23, 191-201 (2017).

42. Leung, G. M. \& Lam, K. S. Diabetic complications and their implications on health care in Asia. Hong Kong Med J 6, 61-68 (2000). 
43. Yu, H. et al. Initiating Characteristics of Early-onset Type 2 Diabetes Mellitus in Chinese Patients. Chin Med J (Engl) 129, 778-784 (2016).

44. Hjelstuen, A., Anderssen, S. A., Holme, I., Seljeflot, I. \& Klemsdal, T. O. Effect of lifestyle and/or statin treatment on soluble markers of atherosclerosis in hypertensives. Scand Cardiovasc J 41, 313-320 (2007).

45. Bolbrinker, J., Zaidi Touis, L., Gohlke, H., Weisser, B. \& Kreutz, R. European guidelines on lifestyle changes for management of hypertension: Awareness and implementation of recommendations among German and European physicians. Herz 43, 352-358 (2018).

46. Li, G. et al. Effects of guideline-based hypertension management in rural areas of Guangdong Province. Chin Med J (Engl) 128, 799-803 (2015).

47. Sio, S. D. et al. Work-related stress and cortisol levels: is there an association? Results of an observational study. Eur Rev Med Pharmacol Sci 22, $9012-9017$ (2018).

48. Jones, C. \& Gwenin, C. Cortisol level dysregulation and its prevalence-ls it nature's alarm clock? Physiol Rep 8, e14644 (2021).

49. Tan, T. et al. Association between high serum total cortisol concentrations and mortality from COVID-19. Lancet Diabetes Endocrino/ 8, 659-660 (2020).

50. Hamrahian, A. H., Oseni, T. S. \& Arafah, B. M. Measurements of serum free cortisol in critically ill patients. $N$ Engl J Med 350, 1629-1638 (2004).

51. Akishita, M. et al. Low testosterone level as a predictor of cardiovascular events in Japanese men with coronary risk factors. Atherosclerosis 210, 232-236 (2010).

52. Estrada-Y-Martin, R. M. \& Orlander, P. R. Salivary cortisol can replace free serum cortisol measurements in patients with septic shock. Chest 140, 1216-1222 (2011).

53. Lazzarino, A. I., Hamer, M., Gaze, D., Collinson, P. \& Steptoe, A. The association between cortisol response to mental stress and high-sensitivity cardiac troponin T plasma concentration in healthy adults. J Am Coll Cardiol 62, 1694-1701 (2013).

54. Lee, D. Y., Kim, E. \& Choi, M. H. Technical and clinical aspects of cortisol as a biochemical marker of chronic stress. BMB Rep 48, 209-216 (2015).

55. Israel E, Banerjee TR, Fitzmaurice GM, Kotlov TV, LaHive K, LeBoff MS. Effects of inhaled glucocorticoids on bone density in premenopausal women. N Engl J Med 345, 941-947 (2001).

56. Wechsler, M. E. et al. NHLBI AsthmaNet. Step-Up Therapy in Black Children and Adults with Poorly Controlled Asthma. N Engl J Med 381, 1227-1239 (2019).

\section{Tables}

Table 1. Clinical characteristics of cases with C-type hypertension (CtH). 


\begin{tabular}{|c|c|c|c|c|}
\hline \multirow[t]{2}{*}{ Items } & Case 1. & Case 2. & Case 3. & Case 4. \\
\hline & $\begin{array}{l}\text { CtH with } \\
\text { arteriosclerosis } \\
\text { and coronary } \\
\text { heart disease }\end{array}$ & $\begin{array}{l}\text { CtH with asymptomatic } \\
\text { but with genetic history }\end{array}$ & $\begin{array}{l}\text { CtH with } \\
\text { symptomatic and } \\
\text { genetic history }\end{array}$ & $\begin{array}{l}\text { CtH with } \\
\text { symptomatic but } \\
\text { no genetic history }\end{array}$ \\
\hline $\begin{array}{l}\text { General } \\
\text { information }\end{array}$ & $\begin{array}{l}\text { Male, } 45 \mathrm{yrs}, \\
\text { married, } \\
\text { construction } \\
\text { contractor }\end{array}$ & $\begin{array}{l}\text { Male, } 51 \text { yrs, married, } \\
\text { elevator maintenance } \\
\text { worker }\end{array}$ & $\begin{array}{l}\text { Female, } 47 \mathrm{yrs}, \\
\text { married, financial } \\
\text { staff }\end{array}$ & $\begin{array}{l}\text { Female, 34yrs, } \\
\text { married, laid-off } \\
\text { workers }\end{array}$ \\
\hline $\begin{array}{l}\text { Chief } \\
\text { complaint }\end{array}$ & $\begin{array}{l}\text { Chest tightness } \\
\text { at night and } \\
\text { palpitation for } \\
\text { half a month }\end{array}$ & $\begin{array}{l}\text { No discomfort, physical } \\
\text { examination for annual } \\
\text { qualification certificate }\end{array}$ & $\begin{array}{l}\text { Chest tightness, } \\
\text { dizziness for 2-3 } \\
\text { years, syncope with } \\
\text { palpitation and cold } \\
\text { sweat for one day }\end{array}$ & $\begin{array}{l}\text { Palpitation, tremor } \\
\text { and insomnia for a } \\
\text { month }\end{array}$ \\
\hline Past history & First visit doctor & $\begin{array}{l}\text { Physical examination } \\
\text { every four years, first twice } \\
\text { results are unknown, Never } \\
\text { see a doctor or take } \\
\text { medicine }\end{array}$ & $\begin{array}{l}\text { Physical } \\
\text { examination found } \\
\text { "high blood } \\
\text { pressure", has not } \\
\text { been treated with } \\
\text { agents }\end{array}$ & No records \\
\hline $\begin{array}{l}\text { Family } \\
\text { history }\end{array}$ & $\begin{array}{l}\text { Two brothers } \\
\text { died of lung } \\
\text { cancer and liver } \\
\text { cancer, } \\
\text { respectively }\end{array}$ & $\begin{array}{l}\text { His father has } \\
\text { hypertension, arrhythmia, } \\
\text { chronic heart failure, his } \\
\text { mother has hypertension, } \\
\text { rheumatism }\end{array}$ & $\begin{array}{l}\text { Her father died of } \\
\text { cardiovascular } \\
\text { disease and her } \\
\text { mother was healthy }\end{array}$ & $\begin{array}{l}\text { Both her father and } \\
\text { mother are healthy }\end{array}$ \\
\hline Environment & Rural life & $\begin{array}{l}\text { City life, has hypertension } \\
\text { with genetic history }\end{array}$ & City life & City life \\
\hline Sleep & $\begin{array}{l}\text { OSA (+++), don't } \\
\text { stay up later }\end{array}$ & $\begin{array}{l}\text { His sleep is good, OSA (-), } \\
\text { Often stay up later until } \\
24: 00 \text { PM }\end{array}$ & $\begin{array}{l}\text { Sleep at } 23: 00- \\
24: 00, \text { sometimes } \\
\text { OSA }(+)\end{array}$ & $\begin{array}{l}\text { Often stay up later } \\
\text { (sleep at } 24: 00- \\
\text { 2:00), and her } \\
\text { sleep was not so } \\
\text { good, OSA (-) }\end{array}$ \\
\hline Emotion & $\begin{array}{l}\text { Work under } \\
\text { great pressure }\end{array}$ & $\begin{array}{l}\text { Less psychological } \\
\text { pressure }\end{array}$ & $\begin{array}{l}\text { Work under little } \\
\text { pressure }\end{array}$ & Bad emotion \\
\hline Exercise & $\begin{array}{l}\text { Physical } \\
\text { inactivity }\end{array}$ & $\begin{array}{l}\text { Physical inactivity, repair } \\
\text { work, go to work by electric } \\
\text { vehicle, take the elevator to } \\
\text { the eighth floor when } \\
\text { getting home, watching TV } \\
\text { often }\end{array}$ & $\begin{array}{l}\text { Physical inactivity, } \\
\text { sitting and using } \\
\text { computers for a } \\
\text { long time (more } \\
\text { than } 10 \text { hrs a day), } \\
\text { do housework }\end{array}$ & $\begin{array}{l}\text { Physical inactivity, } \\
\text { do housework }\end{array}$ \\
\hline Diet & $\begin{array}{l}\text { 80-100 } \\
\text { cigarettes per } \\
\text { day for } 2 \text { years, } \\
\text { liquor drinking } \\
\text { (quarter a } \\
\text { kilogram a } \\
\text { week) }\end{array}$ & $\begin{array}{l}30 \text { cigarettes per day for } \\
30 \text { years, liquor drinking } \\
\text { once a night ( } 2 \text { to } 3 \text { drinks } \\
\text { at a time), drink strong tea }\end{array}$ & $\begin{array}{l}\text { Non-smoking and } \\
\text { alcohol addiction, } \\
\text { but have passive } \\
\text { smoking }\end{array}$ & $\begin{array}{l}\text { Non-smoking and } \\
\text { alcohol addiction, } \\
\text { passive smoking } \\
\text { (her husband } \\
\text { smoking, 20 } \\
\text { cigarettes per day) }\end{array}$ \\
\hline $\begin{array}{l}\text { Blood } \\
\text { pressure }\end{array}$ & $\begin{array}{l}136 / 110 \mathrm{mmHg} \\
\text { (Right), } 136 / 106 \\
\mathrm{mmHg} \text { (Left) }\end{array}$ & $\begin{array}{l}210 / 140 \mathrm{mmHg} \text { (Right), } \\
214 / 140 \mathrm{mmHg} \text { (Left) }\end{array}$ & $\begin{array}{l}156 / 114 \mathrm{mmHg} \\
\text { (Right), 158/122 } \\
\mathrm{mmHg} \text { (Left) }\end{array}$ & $\begin{array}{l}\text { 166/116 mmHg } \\
\text { (Right), 166/116 } \\
\text { mmHg (Left) }\end{array}$ \\
\hline
\end{tabular}




\begin{tabular}{|lllll|} 
BMI & $80+\mathrm{kg} / 1.68 \mathrm{~m}(2)$ & $78 \mathrm{~kg} / 1.67 \mathrm{~m}(2)$ & $56 \mathrm{~kg} / 1.60 \mathrm{~m}(2)$ & $55 \mathrm{~kg} / 1.56 \mathrm{~m}(2)$ \\
\hline Others & - & - & - & $\begin{array}{l}\text { Premature pulse, } \\
\text { thyroid function (-) }\end{array}$ \\
\hline
\end{tabular}

\section{Table 2.}

Preliminary clinical data of patients with $\mathrm{CtH}$ : Blood pressure and cortisol levels.

\begin{tabular}{|lllllll|}
\hline Gender & Age & BMI & $\begin{array}{l}\text { Bp }(\mathrm{R}) \\
(\mathrm{mmHg})\end{array}$ & $\begin{array}{l}\mathrm{Bp}(\mathrm{L}) \\
(\mathrm{mmHg})\end{array}$ & $\begin{array}{l}\text { Cortisol(ng/mL) } \\
\text { F8:00AM }\end{array}$ & Cortisol(ng/mLF4:00PM \\
\hline Male & 49 & 27.68 & $154.00 / 112.00$ & $146.00 / 106.00$ & No record & 312.09 \\
\hline & 52 & 31.14 & $116.00 / 96.00$ & $116.00 / 96.00$ & 257.01 & 168.62 \\
\hline & 55 & 29.05 & No record & $136.00 / 96.00$ & 426.35 & 308.55 \\
\hline Female & 59 & 34.60 & $162.00 / 106.00$ & $146.00 / 96.00$ & 342.18 & No record \\
& 42 & 32.05 & $122.00 / 82.00$ & $126.00 / 86.00$ & No record & 280.09 \\
\hline & 25 & 20.08 & $126.00 / 92.00$ & $122.00 / 88.00$ & 320.00 & 632.00 \\
\hline & 49 & No & $156.00 / 110.00$ & $156.00 / 112.00$ & 385.67 & 467.85 \\
\hline 49 & 23.44 & $152.00 / 96.00$ & $166.00 / 98.00$ & 386.72 & 168.29 \\
\hline 52 & 33.46 & $146.00 / 116.00$ & No record & 301.72 & 156.64 \\
\hline
\end{tabular}


Notes 1: The standard of normal blood pressure can be found in the relevant guidelines, and the normal range of cortisol levels can be found in the instructions of the corresponding test kit.

Notes 2: Cortisol levels were determined by radioimmunoassay kits of Northern Institute of Biotechnology in Beijing. Normal reference values of plasma cortisol levels were 7:00-9:00 (F8:00AM) 66-286 ng/dL, 15:00-17:00 (F4:00PM) 22-154 ng/dL (Data at 24:00 time point were not measured because all the subjects were outpatients).

\section{Table 3.}

Clinical data of patients with $\mathrm{CtH}$ by modified lifestyle and antihypertensive agents: Blood pressure and cortisol levels.

\begin{tabular}{|llllllll|}
\hline Gender & Cases & Age & BMI & $\begin{array}{l}\text { Bp }(\mathrm{R}) \\
(\mathrm{mmHg})\end{array}$ & $\begin{array}{l}\text { Bp }(\mathrm{L}) \\
(\mathrm{mmHg})\end{array}$ & $\begin{array}{l}\text { Cortisol(ng/mL) } \\
\text { F8:00AM }\end{array}$ & $\begin{array}{l}\text { Cortisol(ng/mL) } \\
\text { F4:00PM }\end{array}$ \\
\hline Male & No. 1 & 40 & 28.16 & $128.00 / 102.00$ & $116.00 / 90.00$ & 214.00 & No record \\
\hline & No. 2 & 50 & 24.65 & $176.00 / 128.00$ & $178.00 / 118.00$ & 124.85 & 126.53 \\
\hline Female & No. 3 & 28 & 24.65 & $106.00 / 92.00$ & $112.00 / 86.00$ & 75.80 & 34.00 \\
\hline
\end{tabular}

Notes: Cortisol levels in male patients were measured by radioimmunoassay and in female patients by chemiluminescence.

\section{Table 4.}

Clinical data of healthy population controlled with $\mathrm{CtH}$ : Blood pressure and cortisol levels. 


\begin{tabular}{|llllllll|}
\hline Gender & Cases & Age & $\mathrm{BMI}$ & $\begin{array}{l}\mathrm{Bp}(\mathrm{R}) \\
(\mathrm{mmHg})\end{array}$ & $\begin{array}{l}\mathrm{Bp}(\mathrm{L}) \\
(\mathrm{mmHg})\end{array}$ & $\begin{array}{l}\text { Cortisol(ng/mL) } \\
\text { F8:00AM }\end{array}$ & $\begin{array}{l}\text { Cortisol(ng/mL) } \\
\text { F4:00PM }\end{array}$ \\
\hline Male & No. 1 & 50 & 21.26 & $112.00 / 72.00$ & $115.00 / 76.00$ & 102.80 & 62.70 \\
\hline Female & No. 2 & 40 & 22.49 & $120.00 / 76.00$ & $102.00 / 72.00$ & 107.50 & 64.80 \\
\hline
\end{tabular}

Notes 1: The standard of normal blood pressure can be found in the relevant guidelines, and the normal range of cortisol level can be found in the instructions of the corresponding test kit.

Notes 2: Cortisol levels of healthy population samples in this study was measured by the Chemiluminescence Kit of Di'anhuaxing Medical Laboratory in Jiangxi Province. Normal reference values of plasma cortisol level were 7:00-9:00 (F8:00AM) 67-226 ng/dL, 15:00-17:00 (F4:00PM) less than 100.00 ng/dL (No data at 24:00 time point were measured).

\section{Table 5.}

Preliminary clinical data of elderly patients with hypertension or and diabetes mellitus: Blood pressure and cortisol levels.

\begin{tabular}{|c|c|c|c|c|c|c|c|}
\hline Gender & Cases & Age & BMI & $\begin{array}{l}\mathrm{Bp}(\mathrm{R}) \\
(\mathrm{mmHg})\end{array}$ & $\begin{array}{l}\mathrm{Bp}(\mathrm{L}) \\
(\mathrm{mmHg})\end{array}$ & $\begin{array}{l}\text { Cortisol(ng/mL) } \\
\text { F8:00AM }\end{array}$ & $\begin{array}{l}\text { Cortisol }(\mathrm{ng} / \mathrm{mL}) \\
\text { F4:00PM }\end{array}$ \\
\hline \multirow[t]{4}{*}{ Male } & No. 1 & 73 & 30.07 & $152.00 / 90.00$ & No record & 212.29 & No record \\
\hline & No. 2 & 64 & 24.22 & No record & $174.00 / 114.00$ & 229.92 & 142.90 \\
\hline & No. 3 & 62 & 26.30 & $150.00 / 92.00$ & $122.00 / 92.00$ & 173.70 & 80.20 \\
\hline & No. 4 & 62 & $\begin{array}{l}\text { No } \\
\text { record }\end{array}$ & $156.00 / 112.00$ & $146.00 / 106.00$ & 102.00 & 82.30 \\
\hline Female & No. 5 & 57 & 28.58 & $150.00 / 116.00$ & No record & 140.20 & 101.50 \\
\hline
\end{tabular}

Notes 1: The standard of normal blood pressure can be found in the relevant guidelines, and the normal range of cortisol levels can be found in the instructions of the corresponding test kit.

Notes 2: Cortisol levels were measured by radioimmunoassay in patients 1 and 2, and chemiluminescence in patients 3-5. 


\section{Figures}

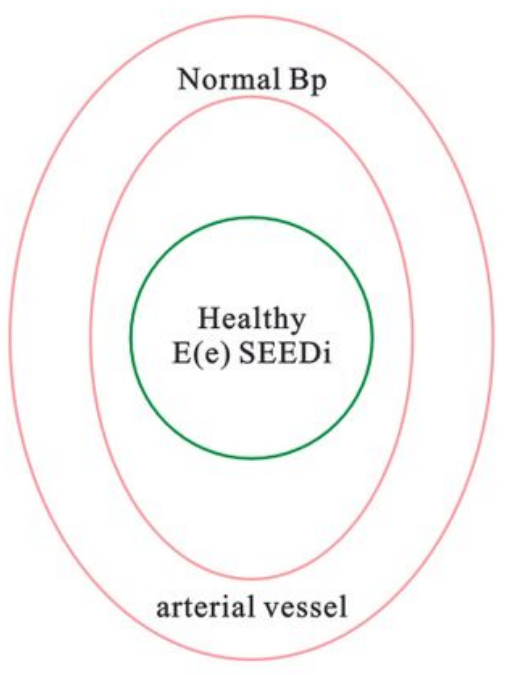

A
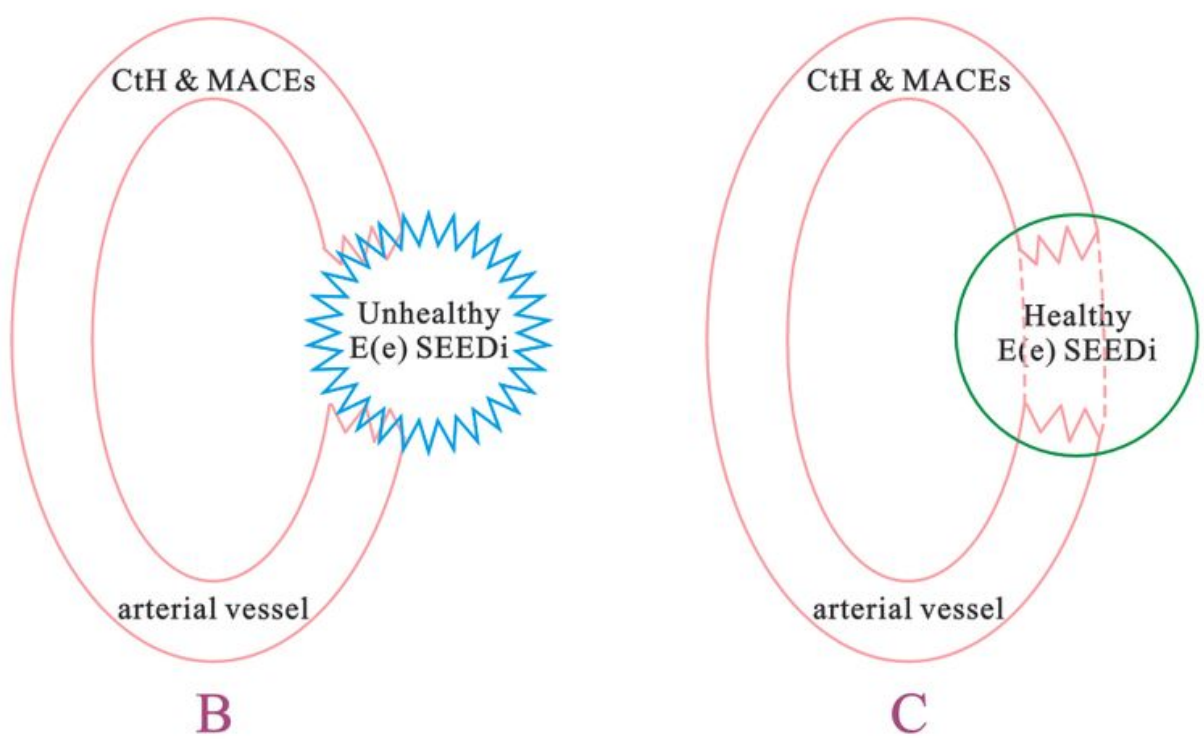

Figure 1

E(e)SEEDi "closures" arterial vessels for adverse outcomes of C-type hypertension (CtH). 